\title{
CHRISTIAN MOSER
}

A WIDE circle of pupils and friends, not only in his native Switzerland but throughout the world of insurance, mourn the death of Dr Christian Moser, Professor of Actuarial Science at Berne University, which took place on 9 th July last. Born on 18 th October, $\mathrm{I} 86 \mathrm{r}$, he became a teacher primarily of mathematics and physics, but took up actuarial subjects in $189 \mathrm{I}$ through interesting himself in national health insurance. His many papers in connection with this brought him fame. He had been an ordinary professor at Berne University since 1887 , but in 1915 he was appointed to the newly-created post for actuarial science there. Meantime, in 1904, he had become head of the Swiss Department for Insurance Supervision. On the occasion of his seventieth birthday, he had an exceptional distinction, for a large number of his pupils presented him with a volume, called the Moser Souvenir, consisting of actuarial papers prepared by twenty-eight of them. The list of names and descriptions is impressive, and the frontispiece photograph of the professor an excellent likeness (see F.I.A. Vol. LXIII, p. I08). As above indicated, his work in connection with state insurance was of great value, and while no general review can be attempted of his activities, reference may be made to the light he threw on the nature of the force of mortality, and to his instructive analyses of the formation of stationary and of varying bodies of lives, i.e. "closed" and "open" series. He was a great teacher, and still more, an outstanding personality.

G. W. R. 